\title{
An Analysis on the Effects of Economic Conditions on Investment Behavior: Focusing on Level of Finance Knowledge, Income-Expenditure Balance and Liquidity Constraints
}

\author{
Kil Woo Han ${ }^{1} \&$ Sang-Bum Park ${ }^{2}$ \\ ${ }^{1}$ Ph.D Student, Dept. of Business Administration, Korea Aerospace University, Korea \\ ${ }^{2}$ Professor, Dept. of Business Administration, Korea Aerospace University, Korea \\ Correspondence: Park, Sang-Bum, Professor, Dept. of Business Administration, Korea Aerospace University, \\ Korea. Tel: 82-10-2579-1437. E-mail: psb@kau.ac.kr
}

Received: October 3, 2019

Accepted: October 21, 2019

Online Published: October 25, 2019

doi:10.5539/ijef.v11n11p52

URL: https://doi.org/10.5539/ijef.v11n11p52

\begin{abstract}
In this study, we investigated the factors that influence investor's propensity to invest which called investment behavior. Factors known to have an impact on individual investment decisions are psychological and cognitive errors, socioeconomic and environmental factors, and financial, economic and environmental factors. Among those factors, financial and environmental factors including the level of knowledge in terms of financial economy, harmonization of income and expenditure, and liquidity constraints are empirically investigated. Among the personal factors the liquidity constraints has been turned out to have significant impact on decision-making about investments.

The findings that liquidity constraints have an impact on the investment behavior and there are differences between investment behaviors according to the purposes of investment, and the liquidity constraints has impact on them have significant meanings. Generally, investment behaviors are kinds of inherent characteristics, in other words, hard to be changed or affected. But the study results indicate that investment behaviors can be affected personal economic conditions.
\end{abstract}

So, when advices or consulting regarding investments is made, not only the person's investment behavior but also the person's economic conditions, especially if the person is under liquidity constraints should be considered. Also, investors should take into accounts his or her economic conditions when making investment decisions.

Keywords: investment behavior, finance knowledge, income-expenditure balance, liquidity constraints

\section{Introduction}

In Korea, as the rate of economic growth has been slow down people started to think investment rather than saving is becoming important. The interest rate used to be high enough not to consider investment which inevitably accompanying risks.

The authorities concerned have focused to protect investors in many respects and researchers and institutions have studies factors affecting investment patterns of personal investors.

In the process of industrialization, savings in accordance with large funding demand were guaranteed, and the general public preferred property growth through saving rather than investment. Since interest rates were guaranteed in savings deposits, such as periodic savings, there was less reason to be interested in investments that were accompanied by risks. However, as the economic growth rate has fallen to single digits, and the interest rate has lowered down even to at $2-3 \%$, people have realized that they would be in a difficult situation to offset inflation with savings only.

Under these circumstances, individuals have a great interest in investing. Naturally, authorities have taken the necessary measures to protect investors, and research institutes and academia have been actively conducting studies on the propensity of investors or investment behavior. In addition, the rapid aging of the population and the massive rise of retirees in the face of insufficient economic and social safety nets have emerged as a new social issue, especially the economic safety issue after retirement. 
Traditionally, in finance literature, researchers have developed the theories under the premise that for investors rational decision-making has been made, but in recent years, rational decision-making has not always been applied, and instead investors' personal inclinations, socio-environmental factors, and financial and economic factors have implications regarding investment decision-making (Shefrin, 2008). It has been reported that phenomena in which decisions are made differently from what has been expected in the traditional models are being observed. These phenomena also appear in preparations for retirement from an economic point of view, a typical case is pension puzzle. Of course, preparing for retirement from a financial point of view is concern about how to secure enough cash flow after retirement. Therefore, there is no exaggeration to say that people are interested in investment.

When an individual wants to invest, there are three factors that can affect it. Many studies have revealed that three factors contribute to an individual's investment behavior, which directly affects their investment. The first factor is personal factors including overconfidence, over-optimism, loss aversion, regret aversion, self-control, and cognitive dissonance (concepts of psychology, judgment and cognitive error). These personal factors play a role as cognitive dissonance, confirmation bias, anchoring, mental accounting and herd behavior (Olsen, 1998; Ritter, 2003).

The second socio-environmental factors are social interactions and influences by social reference groups.

The third factor, the financial and economic factor, is the level of financial knowledge and economic situation that investors have, especially the habits, patterns, and economic instability of the economic life. Such habits and situations related to economic life can be said to be closely related to self-confidence, optimism and self-control.

This study aims to examine the financial, economic and environmental factors that can affect individual investors. Especially, we would like to conduct an empirical analysis on the level of knowledge in terms of finance and the economic situation of individuals affect the investment behavior. The economic situations that the study seeks to examine are the level of knowledge regarding finance, the balance between income and expenditure and the impact of liquidity constraints. Also, the study investigates whether there is any difference between investments for common purposes and investments for retirement in terms of expected level of rate of return and tendency to take risks.

The study results whether external factors, such as liquidity constraints as well as level of finance related knowledge and balance of income and expenditure, affect investment behavior will have significant implication to not only the investor but also advisors and consultants, because current guide lines suggested by the authorities are limited to investor's personal factors. In some cases, it may be necessary to consider the consequences that favorable investment-related decisions made according to the guidelines by the authorities may be distorted ones by the main transition.

\section{Theoretical Background and Precedent Studies}

\subsection{Financial and Economic Factors}

In traditional finance literature, a core assumption of research on investment decision making is rational decision making. In other words, an investor is regarded as rational decision-maker. However, some cases found in practice and some of study results have shown that such assumption does not fit. The findings suggest that investors do not logically judge in investment decision-making. And naturally researches have focused on factors that influence these decision-makings, which seem to be unreasonable. This study seeks to examine the financial and economic factors that are predicted to have an impact on individuals' decision making in terms of investment.

The financial and economic factors related to investment decision making are in fact very difficult because of their wide scope and variety. In a related study, Hershey et al. (2007) have adopted economic and financial knowledge as well as economic insecurity as a factor influencing individual investor's investment decisions.

If the financial and economic factors are divided into external and internal factors centering on the individual investor, external factors are those that arise from the fluctuations of macroeconomic indicators in which the individual investor belongs to, for example, changes in the interest rate, ups and downs of the industry, price instability, employment insecurity and social and economic safety net levels and etc. Internal factors include income, asset size, financial and economic knowledge level, economic life tendency, balanced income and expenditure, and liquidity constraints.

As an individual investor, there will be little or no room to adjust external factors, but only will be able to make predictions about these factors and be prepared for them. In contrast, internal factors may be expected to have some impacts on individual's current decision-making for investments and in the long run, of course, those 
situations of the factors will be changed.

\subsection{Investment Behavior}

1) Definition of concepts

Investment is the act of sacrificing current consumption and expecting profits in the future with uncertain compensation (Park et al., 2010). Investment is a process of ironing that takes place within the temporal framework of the present and the future, and because of the uncertainty in the process, there is always a risk inside it. The level of accepting and responding to risks differs for each investor, and investment decisions will vary depending on how much risk can be taken for future expected returns. These risk acceptance and response levels can be referred to as investment behaviors. Existing previous studies dealing with investment risk, that is, uncertainty about the occurrence of losses, suggest that risk-taking behavior (Grable \& Lytton, 1998) has not yet been clearly agreed upon with a scientific unified concept definition. It can be found that a variety of terms, such as, risk attitude, risk tolerance, risk aversion (Laughhunn, Payne, \& Crum, 1980; March \& Shapira, 1987) are being used.

Risk attitude is a psychological variable that affects individual's investment decisions with consistency and stable personal propensity. Attitudes toward risk for an individual are not absolute concepts, but relative concepts that are placed on a continuous line of risk taking and hedges. Risk attitude refers to the recognition of investment risk in relation to sentiment psychology and is divided into risk aversion, risk neutrality and risk pursuit (Krzysztofowicz, 1983; Kim, 1987).

After all, investment behavior can be considered as a concept that includes risk acceptance tendency and risk sensitivity including risk attitude, and it is a concept that has been settled in practice. In this context, the concept of investment behavior is similar to the concept of person's propensity or tendency in terms of decision-making regarding investment.

\section{2) Classification of investment behavior}

According to Article 46, Paragraph 2 of the Law on Capital Markets and Financial Investment Business in Korea, the investment behavior is divided as follows. As we can see, the steps are divided according to the level of risk tolerance and the expected level of investment return.

(1) Stable: Expect to achieve a positive return on deposits and does not want to incur losses on investment principals. However, short-term losses can be accepted for profit, and some of the assets are willing to invest in products with high volatility in order to generate higher returns than deposits. If you can expect higher returns than your savings, you may be able to take some risk of loss.

(2) Safety: minimize the loss risk and want to safe investment with the income level of interests from savings deposit or dividend. but intend to accept temporary loss for higher return and to invest part of property in products with relatively high volatility for higher return than safety deposit

(3) Risk neutral: understand investment risk and ready to accept certain level of risk of loss for higher level of return than safety deposit

(4) Active investment type: Seek to realize a high level of ROI even if the risk is tolerated rather than the protection of investment capital. Investors are willing to invest a substantial portion of their equity, equity funds, or derivatives,

(5) aggressive investment type: seeks a high level of return on investment that far exceeds the market average return. Actively accept risks of loss. Most investors are willing to invest in risky assets such as stocks, equity funds or derivatives.

The effects of above distinction of investment behavior are on the recommendation of indirect investment, so as to recommend appropriate investment products suitable for the investor's propensity to invest, and is also on the investor's decision-making, so as to make the investment according to their own propensity to manage the assets based on his/her own propensity.

\subsection{Financial and Economic Factors and Investment Behavior}

The fact that personal factors, such as, psychological judgment and cognitive error social, environmental factors, and financial and environmental factors affect personal investment decisions has been partially revealed through previous studies. In investment-related decision-making, it can be concluded that such personal and social factors, financial and economic factors, and so forth, have a certain level of influence on the investment behaviors formed inherently. 
This study aims to examine whether the financial and economic factors that have been recognized to affect the investment behavior empirically. The financial and environmental factors are known to be level of finance related knowledge and economic conditions, particularly the habits and patterns of economic life, and the impact of economic instability.

The propensity of individuals throughout the economic life can be analyzed by looking at whether they are planning to manage their economic life, whether they are able to control their own spending, and whether they can properly control their own economic future. The level of economic anxiety, and the level of knowledge about the financial economy will also affect the economic life as a factor.

\section{Research Method}

\subsection{Research Design}

In this study, we examine whether investor's personal factors affect the investment behavior or not. Especially, it is intended to analyze the influence of finance and economy related factors on the person's investment behavior. That is, the level of finance and economy related knowledge, harmony of income and expenditure, liquidity constraints that reflects a person's economic condition and attitudes towards economic preparation and scheme are examined as factors affecting investment behavior. Also, if there is difference on the expectation level of return and on the level of acceptable risks between common investment and investment for retirement is analyzed.

We can admit that the knowledge and information affect decision-making without doubt, in general. The harmonization of income expenditure reflects the planning and control ability of individuals as they go about their own economic life. And the liquidity constraint reflects the level of income and planning of the individual, reflecting the current economic conditions and economic instability. Also, liquidity constraints are the results of those. This is because the definition of liquidity constraints is a measure of how much we can prepare for the interruption of current income or sudden expenditures. In this context, it is possible to foresee that liquidity constraints may have some impact, even in preparation for the future. Liquidity constraints can be defined as lack of borrowing amounts from financial institutions by his/her future incomes as collateral. However, this definition is hard to measure for research. So, we will define liquidity constrains as certain portion of liquid form of assets of his/her annual income. This definition reflects to what extent they can spend even if their income is cut off and the level of preparation of his/her for economic hardship.

Accordingly, this study seeks to identify the individual's inclinations, especially as an investor through the harmonization of income and expenditures and the constraint of liquidity, and to see if these factors affect the investment inclination.

In addition, it is possible to predict that the access postures will be different in the case of ordinary investments in relation to the investment tendency and the expectation of the investment performance, and in the case of investment for funding for retirement. In the case of a normal investment, factors such as the investor's investment tendency, given conditions, etc., will have an influence on it, and if it is a fund for retirement, in addition to the usual investment period, the investment period will be long-term, and investors will try to minimize the time-to-error. It is likely that the desires you want to work will be more likely to work, but you may not be able to distinguish between the usual investments and the funding for retirement to organize different accounts and take different investments. The hypotheses are set up for the research on these research topics.

Hypothesis 1. The individual's personal factors will affect investment behavior.

Hypothesis 1-1. The level of finance and economic knowledge will affect investment behavior.

Hypothesis 1-2. The capability to control income expenditure will have an effect on investment behavior.

Hypothesis 1-2. Individual's liquidity constraints will have an impact on investment behavior.

Hypothesis 2. Individual's economic condition, especially liquidity constraints will affect the level of expected return and risks depending on whether the investment is for common purposes or for retirement.

\subsection{Research Method}

For the purpose of this study, a survey was conducted. The questionnaire includes a question asking to choose one of the five steps of investment behavior from the lowest risk tolerance step to highest risk tolerance step. Also, questions asking to show how well manage income and expenditure, financial and economic knowledge level, and how is the liquidity constraints. It consists of questions asking the level of expected return when investing for common purposes and for retirement, and questions about income levels, asset size and gender distinction. 
450 questionnaires were distributed randomly and 413 were collected, and among them 399 were used for final analysis. The analysis was carried out using the SPSS program to conduct multinomial logistic analysis and ANOVA analysis.

\section{Analysis Results}

\subsection{Test Results of Hypothesis 1}

Analysis of the impact of the level of financial and economic knowledge, the balance of income and expenditure, and the impact of liquidity constraints on investment behavior

The results of the multi-term logit analysis using investment behavior as dependent variable, and finance and economy knowledge level, income and expenditure balance, liquidity constraint, gender, income level, and asset size as independent variables are as follows.

Table 1. Multinomial logit analysis model fitness

\begin{tabular}{lcccc}
\hline \multicolumn{4}{c}{ Model fit information } \\
\hline Model custom criteria & & Likelihood ratio test & \\
\hline Model & -2 log likelihood & Chi square & Degree of freedom & Significance prob. \\
\hline Intercept only & 270.043 & & & \\
Final model & 238.225 & 31.819 & 20 & 0.045 \\
\hline
\end{tabular}

From the table above, we can see that the model's suitability is statistically significant at the 0.05 level. The following table show the results of the multinomial logit test.

Table 2. Results of multinomial logit analysis

\begin{tabular}{|c|c|c|c|c|}
\hline \multicolumn{5}{|c|}{ Likelihood ratio test } \\
\hline \multirow[b]{2}{*}{ Effect } & \multirow{2}{*}{$\begin{array}{c}\text { Model custom criteria } \\
\text { Reduced -2 log likelihood }\end{array}$} & \multicolumn{3}{|c|}{ Likelihood ratio test } \\
\hline & & Chi square & $\mathrm{D} / \mathrm{F}$ & Sig. Prob. \\
\hline Intercept & $238.225 \mathrm{a}$ & .000 & 0 & - \\
\hline Knowledge level & $243.632 b$ & 5. 407 & 4 & .248 \\
\hline Balance of Income and exp. & $243.612 b$ & 4.980 & 4 & .301 \\
\hline Liquidity constraints & 249.638 & 11.413 & 4 & .022 \\
\hline Level of income & 245.870 & 7.646 & 4 & .105 \\
\hline Asset size & 240.512 & 2.288 & 4 & .683 \\
\hline Gender & 239.254 & 1.029 & 4 & .905 \\
\hline
\end{tabular}

In the table above, knowledge level, harmonization of income expenditure, gender, income level and asset size are turned out to have not statistically significant influence on investment behavior, but liquidity constraints have statistically significant effect on investment behavior at 0.05 level.

\subsection{Test Results of Hypothesis 2}

Analysis of the difference between common purpose investment and investment for preparing for retirement in terms of risk tolerance and level of expected return

The results of the questionnaires asking the levels of safety and expected return for common purposes or for preparing for retirement with regards to investment are as follow.

First, in the case of normal investment, for investment behavior step, the average value of 1.54 which is the value of investment behavior steps between (1) Stable and (2) Safety is shown is shown.

Table 3. Results of investment behavior for normal investment

\begin{tabular}{cccccc}
\hline & $\mathrm{N}$ & minimum value & maximum value & average & standard deviation \\
\hline Normal investment & 399 & 1 & 5 & 1.54 & .748 \\
\hline
\end{tabular}

The following is the results of the investment behavior for investing for preparing for retirement. 
Table 4. Results of investment behavior for investment for preparing for retirement

\begin{tabular}{cccccc}
\hline & $\mathrm{N}$ & minimum value & maximum value & average & standard deviation \\
\hline Investment for retirement & 399 & 1 & 5 & 1.62 & .764 \\
\hline
\end{tabular}

Table 3 and table 4 indicate that for the case of investment for retirement the investment behavior is a little more risk-taking and seeking higher expected rate of return. When investing in retirement preparations, it is expected that preparations are usually made over a long period of time, and that there is a high possibility of being biased towards safety-oriented investments in terms of preparation for retirement. However, the results of the survey shown in the above tables are different from what we expected. We further analyzed whether liquidity constraints affect the decision making in terms of investment based on for common purpose or for preparation for retirement. The following table shows the results.

Table 5. The results of analysis of impact of liquidity constraints on variance

\begin{tabular}{ccccccc}
\hline & & Sum of squares & df & mean squared & F & significance probability \\
\hline For & Inter-group & 9.940 & 1 & 9.940 & 18.261 & .000 \\
Common & Within a group & 324.965 & 397 & .544 & - & - \\
purposes & Sum & 334.905 & 398 & & & 11.138 \\
For & Inter-group & 6.396 & & 1 & 6.396 & - \\
preparing for & Within a group & 342.820 & 397 & .574 & - & \\
retirement & Sum & 349.215 & 398 & & & \\
\hline
\end{tabular}

We can see that there are significant differences in the investment behavior depending on the liquidity constraints. The following table shows the results of analyzing impacts of liquidity constraints on investment behavior for the cases of for common purposes and for retirement

Table 6. The results of analysis of differences of investment behavior according to liquidity constraints

\begin{tabular}{|c|c|c|c|c|c|c|c|c|c|}
\hline & & \multirow[t]{2}{*}{$\mathrm{N}$} & \multirow[t]{2}{*}{ Average } & \multirow[t]{2}{*}{ Std. dev. } & \multirow[t]{2}{*}{ Std. error } & \multicolumn{2}{|c|}{$95 \%$ conf. interval for the mean } & \multirow[t]{2}{*}{ Min. val. } & \multirow[t]{2}{*}{ Max. val. } \\
\hline & & & & & & lower limit & upper limit & & \\
\hline For & no liq. const. & 151 & 1.69 & .804 & .051 & 1.59 & 1.79 & 1 & 5 \\
\hline Common & liq. const. & 248 & 1.43 & .686 & .037 & 1.36 & 1.50 & 1 & 5 \\
\hline purposes & sum & 399 & 1.54 & .748 & .031 & 1.48 & 1.60 & 1 & 5 \\
\hline For & no liq. const. & 151 & 1.74 & .765 & .048 & 1.65 & 1.84 & 1 & 5 \\
\hline retirement & liq. const. & 248 & 1.53 & .753 & .040 & 1.45 & 1.61 & 1 & 5 \\
\hline purposes & sum & 399 & 1.62 & .764 & .031 & 1.56 & 1.68 & 1 & 5 \\
\hline
\end{tabular}

From the above table, groups without liquidity constraints tend to seek more profitability for common investment compared to groups with liquidity constraints. This is due to the bias of group without liquidity constraints towards pursuing more safety and profitability in investments for both normal investment and retirement preparation compared to that of group with liquidity constraints. These results are consistent with Kwon Hyun's study (2007), which suggests that people with the higher income risks tend to prefer safer assets.

\section{Conclusion}

In this study, we investigated the factors that influence investor's propensity to invest which called investment behavior. Factors known to have an impact on individual investment decisions are psychological and cognitive errors, socioeconomic and environmental factors, and financial, economic and environmental factors. Among those factors, financial and environmental factors including the level of knowledge in terms of financial economy, harmonization of income and expenditure, and liquidity constraints are empirically investigated. Among the personal factors the liquidity constraints has been turned out to have significant impact on decision-making about investments.

Liquidity constraints reflect person's income and economic planning, the current economic conditions, and the degree of economic insecurity. This is because the definition of liquidity constraints is a measure of how much a person is prepared for the interruption of current income or sudden expenditures. In this context, it is possible to foresee that liquidity constraints may have some impact, even in preparation for the future. Liquidity constraints 
also can be defined as lack of borrowing amounts from financial institutions by his/her future incomes as collateral. This definition is meaningful in terms of indicating a person's economic conditions, however, this definition is hard to measure for research. So, we will define liquidity constrains as certain portion of liquid form of assets of his/her annual income. This definition reflects to what extent they can spend even if their income is cut off and the level of preparation of his/her for economic hardship

The findings that liquidity constraints have an impact on the investment behavior and there are differences between investment behaviors according to the purposes of investment, and the liquidity constraints has impact on them have significant meanings. Generally, investment behaviors are kinds of inherent characteristics, in other words, hard to be changed or affected. But the study results indicate that investment behaviors can be affected personal economic conditions.

So, when advices or consulting regarding investments is made, not only the person's investment behavior but also the person's economic conditions, especially if the person is under liquidity constraints should be considered. Also, investors should take into accounts his or her economic conditions when making investment decisions.

\section{References}

Grable, J. E., \& Lytton, R. H. (1999). Assessing financial risk tolerance: Do demographic, socioeconomic, and attitudinal factors work. Family Relations and Human Development/Family Economics and Resource Management Biennial, 3, 80-88.

Hershey, D. A., Jacobs-Lawson, J. M., McArdle, J. J., \& Hamagami, F. (2007). Psychological foundations of financial planning for retirement. Journal of Adult Development, 14(1-2), 26-36. https://doi.org/10.1007/s10804-007-9028-1

Kim, C. H. (1987). Investment select behavior and utility, Journal of Social Science Research, 7(1), pp.127-143.

Krzysztofowicz, R. (1983). Strength of preference and risk attitude in utility measurement. Organizational Behavior and Human Performance, 31(1), 88-113. https://doi.org/10.1016/0030-5073(83)90114-9

Laughhunn, D. J., Payne, J. W., \& Crum, R. (1980). Managerial risk preferences for below-target returns. Management Science, 26(12), 1238-1249. https://doi.org/10.1287/mnsc.26.12.1238

March, J. G., \& Shapira, Z. (1987). Managerial perspectives on risk and risk taking. Management science, 33(11), 1404-1418. https://doi.org/10.1287/mnsc.33.11.1404

Olsen, R. (1998). Behavioural finance and its implications for stock price volatility. Financial Analysts Journal, 54(2), 10-18. https://doi.org/10.2469/faj.v54.n2.2161

Park, K. S., Yang, J. Y., and Ju, S. H. (2010). Personal Financial Planning. Kyung Publishing Co., Seoul.

Ritter, J. R. (2003). Behavioral finance. Pacific-Basin Finance Journal, 11(4), 429-437. https://doi.org/10.1016/S0927-538X(03)00048-9

Shefrin, H. (2008). A behavioral approach to asset pricing. Elsevier.

\section{Copyrights}

Copyright for this article is retained by the author(s), with first publication rights granted to the journal.

This is an open-access article distributed under the terms and conditions of the Creative Commons Attribution license (http://creativecommons.org/licenses/by/4.0/). 